$9-29-2021$

\title{
A New Generating Family of Distributions: Properties and Applications to the Weibull Exponential Model
}

\author{
El-Sayed A. El-Sherpieny \\ Cairo University, ahmedc55@yahoo.com \\ Salwa Assar \\ Cairo University, salwaassar@yahoo.com \\ Tamer Helal \\ Cairo University, tamerhelal2006@yahoo.com
}

Follow this and additional works at: https://digitalcommons.wayne.edu/jmasm

Part of the Applied Statistics Commons, Social and Behavioral Sciences Commons, and the Statistical Theory Commons

\section{Recommended Citation}

El-Sherpieny, E-S. A., Assar, S., Helal, T. (2020). A New Generating Family of Distributions: Properties and Applications to the Weibull Exponential Model. Journal of Modern Applied Statistical Methods, 19(1), eP2996. https://doi.org/10.22237/jmasm/1608553740

This Regular Article is brought to you for free and open access by the Open Access Journals at DigitalCommons@WayneState. It has been accepted for inclusion in Journal of Modern Applied Statistical Methods by an authorized editor of DigitalCommons@WayneState. 


\title{
A New Generating Family of Distributions: Properties and Applications to the Weibull Exponential Model
}

\author{
El-Sayed A. El-Sherpieny \\ Cairo University \\ Cairo, Egypt
}

\author{
Salwa Assar \\ Cairo University \\ Cairo, Egypt
}

\author{
Tamer Helal \\ Cairo University \\ Cairo, Egypt
}

\begin{abstract}
A new method for generating family of distributions was proposed. Some fundamental properties of the new proposed family include the quantile, survival function, hazard rate function, reversed hazard and cumulative hazard rate functions are provided. This family contains several new models as sub models, such as the Weibull exponential model which was defined and discussed its properties. The maximum likelihood method of estimation is using to estimate the model parameters of the new proposed family. The flexibility and the importance of the Weibull-exponential model is assessed by applying it to a real data set and comparing it with other known models.
\end{abstract}

Keywords: T-X Family, Weibull exponential distribution, Quantile, Maximum likelihood estimation

\section{Introduction}

Many statisticians have made efforts to develop new families of continuous probability distributions. Some well-known family of distributions are: the beta generated family of distributions studied by Eugene et al. (2002), McDonald generated family of distributions studied by Alexander et al. (2012), Weibull-X family of distributions proposed by Alzaatreh et al. (2013), Lomax generated family of distributions introduced by Cordeiro et al. (2012), gamma-X family of distributions studied by Alzaatreh et al. (2014), Kumaraswamy Marshall-Olkin generated family of distributions proposed by Alizadeh et al. (2015), Garhy generated family of distributions introduced by Elgarhy et al. (2016), the Kumaraswamy Weibull generated family of distributions proposed by Hassan and

doi: 10.22237/jmasm/1608553740 | Accepted: Sept 20, 2018; Published: Sept 29, 2021.

Correspondence: Tamer Helal, tamerhela12006@yahoo.com 


\section{EL-SHERPIENY ET AL.}

Elgarhy (2016), Type II half logistic-G by Hassan et al. (2017), exponentiated extended generated family of distributions proposed by Elgarhy et al. (2017), generalized odd log-logistic generated family of distributions studied by Cordeiro et al. (2017), Odd Fréchet generated family of distributions proposed by Haq and Elgarhy (2018), Muth generated family of distributions studied by Almarashi and Elgarhy (2018), A new Weibull-X family of distributions discussed by Ahmad et al. (2018), truncated Cauchy power generated family of distributions discussed by Aldahlan et al. (2020), transmuted odd Fréchet generated family of distributions proposed by Badr et al. (2020), Topp-Leone odd Fréchet generated family of distributions studied in Al-Marzouki et al. (2020) and among others.

Alzaatreh et al. (2013) introduced a new family of distributions is called the $\mathrm{T}-\mathrm{X}$ family with the cumulative distribution function (cdf) defined as

$$
F(x)=\int_{0}^{W(G(x))} r(t) d t
$$

where $W(G(x))$ be a function of $G(x)$. The corresponding probability density function (pdf) to the $\operatorname{cdf}(1)$ is given by

$$
f(x)=\left\{\frac{\partial}{\partial x} W[G(x ; \zeta)]\right\} r\{W[G(x ; \zeta)]\} .
$$

Note the upper limit for generating the T-X distribution is transformation $W[G(x)]=-\log [1-G(x, \zeta)], \zeta$ is the set of parameters. It is possible to define a different upper limit for generating different types of T-X distributions. The transformation $W[G(x)]$ satisfies the following two conditions: $W[G(x)] \in(0, \infty)$ and it is a monotonic non decreasing function. In this paper, the upper limit was defined to be $\alpha^{\log \left[\frac{G(x, \zeta)}{1-G(x, \zeta)}\right]}$ which leads to a new family of exponentiated T-X distributions. By including the additional parameter $\alpha$, the new T-X family provides more flexible distributions for fitting real data. Table 1 provides some $W[G(x)]$ functions for some members of the T-X family. 


\section{A NEW GENERATING FAMILY OF DISTRIBUTIONS}

Table 1. Members of T-X Family

\begin{tabular}{lll}
$\boldsymbol{W} G(\boldsymbol{x})]$ & Range of $\boldsymbol{T}$ & Members of T-X Family \\
\hline$G(x, \zeta)$ & $(\mathbf{0}, \mathbf{1})$ & Beta-G (Eugene et al., 2002), Mc-G (Alexander et al., 2012) \\
$-\log [G(x, \zeta)]$ & $(\mathbf{0}, \infty)$ & Gamma-G Type-2 (Ristić and Balakrishnan, 2012) \\
$-\log [1-G(x, \zeta)]$ & $(\mathbf{0}, \infty)$ & Gamma-G Type-1 (Zografos and Balakrishnan, 2009) \\
$\frac{G(x, \zeta)}{1-G(x, \zeta)}$ & $(\mathbf{0}, \infty)$ & Gamma-G Type-3 (Torabi and Montazeri, 2012) \\
$-\log \left[1-G^{\alpha}(x, \zeta)\right]$ & $(\mathbf{0}, \infty)$ & Exponentiated T-X (Alzaghal et al., 2013) \\
$\log \left[\frac{G(x, \zeta)}{1-G(x, \zeta)}\right]$ & $(-\infty, \infty)$ & Logistic-G (Torabi and Montazeri, 2014) \\
$\log [-\log [1-G(x, \zeta)]]$ & $(-\infty, \infty)$ & The Logistic-X Family (Tahir et al., 2015) \\
$\alpha^{\log \left[\frac{G(x, \zeta)}{1-G(x, \zeta)}\right]}$ & $(\mathbf{0}, \infty)$ & New T-X Family (Proposed) \\
\hline
\end{tabular}

\section{The New T-X Family}

Let $r(t)$ which was defined in (1) be the pdf of a non-negative continuous random variable $T$ defined on $[0, \infty)$, and let $F(x)$ denote the cdf of a random variable $X$. We define the cdf for the new T-X (NT-X) class of distributions for a random variable $X$ as follows

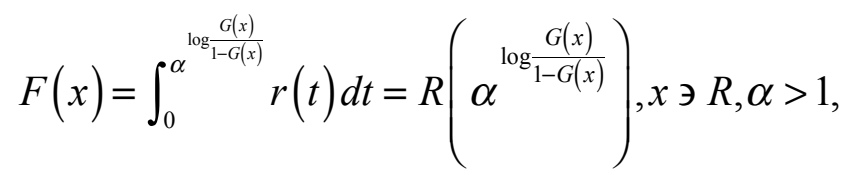

where $R(t)$ is the cdf of the random variable $T$. The corresponding pdf of the generalized distribution in (3) is given by

$$
f(x)=\alpha^{\log \frac{G(x)}{1-G(x)}} \frac{g(x) \log \alpha}{G(x)(1-G(x))} r\left(\alpha^{\log \frac{G(x)}{1-G(x)}}\right), \alpha>1, x \in \mathbb{R} .
$$

The survival function, hazard rate function (hrf), reversed hazard function and cumulative hazard rate function of the NT-X are given respectively by 


\section{EL-SHERPIENY ET AL.}

$$
\begin{gathered}
S(x)=1-R\left(\alpha^{\left.\log \frac{G(x)}{1-G(x)}\right),}\right. \\
h(x)=\frac{\alpha^{\log \frac{G(x)}{1-G(x)}} \frac{g(x) \log \alpha}{G(x)(1-G(x))} r\left(\alpha^{\left.\log \frac{G(x)}{1-G(x)}\right)}\right.}{1-R\left(\alpha^{\log \frac{G(x)}{1-G(x)}}\right)}, \\
\tau(x)=\frac{\alpha^{\log \frac{G(x)}{1-G(x)}} \frac{g(x) \log \alpha}{G(x)(1-G(x))} r\left(\alpha^{\log \frac{G(x)}{1-G(x)}}\right)}{1-R\left(\alpha^{\log \frac{G(x)}{1-G(x)}}\right)},
\end{gathered}
$$

and

$$
H(x)=-\ln \left(1-R\left(\alpha^{\log \frac{G(x)}{1-G(x)}}\right)\right) .
$$

The quantile function for NT-X distribution, $Q(u), 0<u<1$, is obtained by solving $G(Q(u))=u$, which is given by

$$
Q(u)=G^{-1}\left(\frac{e^{\frac{\log R^{-1}(u)}{\log \alpha}}}{1+e^{\frac{\log R^{-1}(u)}{\log \alpha}}}\right) .
$$




\section{Some Members of New T-X Family with Different T- Distributions}

\section{New Fréchet -X Family of distributions}

Consider a random variable $X$ has the Fréchet distribution with cdf given by $R(t)=e^{-\left(\frac{\gamma}{t}\right)^{\theta}}, t, \gamma, \theta>0$, where $\theta$ is a shape parameter and $\gamma$ is a scale parameter and the corresponding pdf is given as $r(t)=\theta \gamma^{\theta} t^{-(\theta+1)} e^{-\left(\frac{\gamma}{t}\right)^{\theta}}$. The cdf and pdf of the new Fréchet $-\mathrm{X}$ (NF-X) family of distributions are obtained respectively by using the cdf in (3) and the pdf in (4) as follows

$$
F(x)=e^{-\left(\frac{\gamma}{\log ^{\log \frac{G(x)}{1-G(x)}}}\right)^{\theta}}, t>0, \gamma, \theta>0, \alpha>1,
$$

and the corresponding pdf is given by

$$
f(x)=\left(\alpha^{\log \frac{G(x)}{1-G(x)}}\right)^{-\theta} \frac{\theta \gamma^{\theta} g(x) \log \alpha}{G(x)(1-G(x))} e^{-\left(\frac{\gamma}{\alpha^{\log \frac{G(x)}{1-G(x)}}}\right)^{\theta}} .
$$

The survival function, hazard rate function, reversed hazard function and cumulative hazard rate function of the NF-X are given respectively by

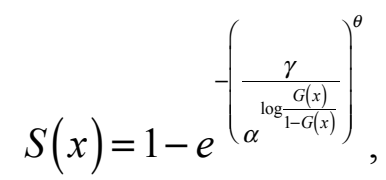




\section{EL-SHERPIENY ET AL.}

$$
\begin{gathered}
h(x)=\frac{\left(\alpha^{\left.\log \frac{G(x)}{1-G(x)}\right)^{-\theta}} \frac{\theta \gamma^{\theta} g(x) \log \alpha}{G(x)(1-G(x))} e^{-\left(\frac{\gamma}{\alpha^{\log \frac{G(x)}{1-G(x)}}}\right)^{\theta}}\right.}{-\left(\frac{\gamma}{\left.\log ^{\log \frac{G(x)}{1-G(x)}}\right)^{\theta}}\right.}, \\
\tau(x)=\left(\alpha^{\log \frac{G(x)}{1-G(x)}}\right)^{-\theta} \frac{\theta \gamma^{\theta} g(x) \log \alpha}{G(x)(1-G(x))}
\end{gathered}
$$

and

$$
H(x)=-\ln \left(1-e^{-\left(\frac{\gamma}{\alpha^{\log \frac{G(x)}{1-G(x)}}}\right)^{\theta}}\right) .
$$

\section{New Lomax-X Family of distributions}

Consider the Lomax random variable $X$ with cdf given by $R(t)=1-(1+\lambda t)^{-k}, t, \lambda, k>0$, and pdf $r(t) \lambda k(1+\lambda t)^{-k-1}$ respectively. The cdf of the new Lomax-X (NL-X) family of distributions is obtained by using the cdf of Lomax in (3) as follows

$$
F(x)=1-\left(1+\lambda \alpha^{\log \frac{G(x)}{1-G(x)}}\right)^{-k}, x>0 ; \lambda, k \text { and } \alpha>1,
$$

and the corresponding pdf is given by 


\section{A NEW GENERATING FAMILY OF DISTRIBUTIONS}

$$
f(x)=\alpha^{\log \frac{G(x)}{1-G(x)}} \frac{\lambda k g(x) \log \alpha}{G(x)(1-G(x))}\left(1+\lambda \alpha^{\log \frac{G(x)}{1-G(x)}}\right)^{-k-1} .
$$

The survival function, hazard rate function, reversed hazard function and cumulative hazard rate function of the NL-X are given respectively by

$$
\begin{aligned}
& S(x)=\left(1+\lambda \alpha^{\log \frac{G(x)}{1-G(x)}}\right)^{-k} \\
& h(x)=\alpha^{\log \frac{G(x)}{1-G(x)}} \frac{\lambda k g(x) \log \alpha}{G(x)(1-G(x))}\left(1+\lambda \alpha^{\log \frac{G(x)}{1-G(x)}}\right)^{-1}, \\
& \tau(x)=\frac{f(x)=\alpha^{\log \frac{G(x)}{1-G(x)}} \frac{\lambda k g(x) \log \alpha}{G(x)(1-G(x))}\left(1+\lambda \alpha^{\left.\log \frac{G(x)}{1-G(x)}\right)^{-k-1}}\right.}{1-\left(1+\lambda \alpha^{\left.\log \frac{G(x)}{1-G(x)}\right)^{-k}}\right.},
\end{aligned}
$$

and

$$
H(x)=-\ln \left(\left(1+\lambda \alpha^{\log \frac{G(x)}{1-G(x)}}\right)^{-k}\right)
$$

\section{New Burr-X Family of distributions}

Consider the Burr random variable $X$ with cdf given by $R(t)=1-\left(1+t^{\lambda}\right)^{-k}$, $t, \lambda, k>0$, and pdf $r(t)=\lambda k t^{\lambda-1}\left(1+t^{\lambda}\right)^{-k-1}$ respectively. The cdf of the new Burr-X (NB-X) family of distributions is obtained by using the cdf of Burr in (3) as follows 


\section{EL-SHERPIENY ET AL.}

$$
f(x)=1-\left(1+\left(\alpha^{\log \frac{G(x)}{1-G(x)}}\right)^{\lambda}\right)^{-k}, x>0 ; \lambda, k>0, \alpha>1,
$$

The corresponding pdf, survival, hazard, reversed hazard and cumulative hazard rate functions are given respectively by

$$
\begin{aligned}
& f(x)=\left(\alpha^{\log \frac{G(x)}{1-G(x)}}\right)^{\lambda} \frac{\lambda k g(x) \log \alpha}{G(x)(1-G(x))}\left(1+\left(\alpha^{\log \frac{G(x)}{1-G(x)}}\right)^{\lambda}\right)^{-k-1}, \\
& S(x)=\left(1+\left(\alpha^{\log \frac{G(x)}{1-G(x)}}\right)^{\lambda}\right)^{-k} \\
& h(x)=\left(\alpha^{\log \frac{G(x)}{1-G(x)}}\right)^{\lambda} \frac{\lambda k g(x) \log \alpha}{G(x)(1-G(x))}\left(1+\left(\alpha^{\log \frac{G(x)}{1-G(x)}}\right)^{\lambda}\right)^{-1}, \\
& \tau(x)=\frac{\left(\alpha^{\log \frac{G(x)}{1-G(x)}}\right)^{\lambda} \frac{\lambda k g(x) \log \alpha}{G(x)(1-G(x))}\left(1+\left(\alpha^{\log \frac{G(x)}{1-G(x)}}\right)^{\lambda}\right)^{-k-1}}{1-\left(1+\left(\alpha^{\log \frac{G(x)}{1-G(x)}}\right)^{\lambda}\right)^{-k}}
\end{aligned}
$$

and

$$
H(x)=-\ln \left(\left(1+\left(\alpha^{\log \frac{G(x)}{1-G(x)}}\right)^{\lambda}\right)^{-k}\right)
$$




\section{A NEW GENERATING FAMILY OF DISTRIBUTIONS}

\section{New Weibull-X Family of distributions}

Consider the cdf of the two-parameter Weibull model with shape parameter $\gamma>0$ and scale parameter $\lambda>0$ given by $R(t)=1-e^{-\lambda t^{\gamma}}, t>0$, and its pdf as $r(t)=\gamma \lambda t^{\gamma-1} e^{-\lambda t^{\gamma}}$. The cdf of the new Weibull-X (NW-X) family of distributions is obtained by using the cdf of Weibull in (3) as follows

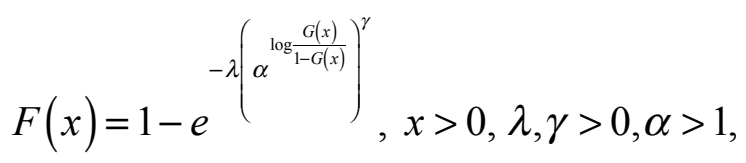

and the corresponding pdf is given by

$$
f(x)=\left(\alpha^{\log \frac{G(x)}{1-G(x)}}\right)^{\gamma} \frac{\gamma \lambda g(x) \log \alpha}{G(x)(1-G(x))} e^{-\lambda\left(\alpha^{\left.\log \frac{G(x)}{1-G(x)}\right)^{\gamma}} .\right.}
$$

The pdf (12) reduces to the new Rayleigh-X (NR-X) family of distributions for $\gamma=2$ and the new exponential-X (NE-X) family of distributions for $\gamma=1$ as special cases from the new Weibull-X (NW-X) family of distributions.

The survival function, hazard rate function, reversed hazard function and cumulative hazard rate function of the NW-X are given respectively by

$$
\begin{gathered}
S(x)=e^{-\lambda\left(\alpha^{\left.\log \frac{G(x)}{1-G(x)}\right)^{\gamma}},\right.} \\
h(x)=e^{-\lambda\left(\alpha^{\log \frac{G(x)}{1-G(x)}}\right)^{\gamma}} \frac{\gamma \lambda g(x) \log \alpha}{G(x)(1-G(x))},
\end{gathered}
$$




\section{EL-SHERPIENY ET AL.}

$$
\tau(x)=\frac{\left(\alpha^{\left.\log \frac{G(x)}{1-G(x)}\right)^{\gamma}} \frac{\gamma \lambda g(x) \log \alpha}{G(x)(1-G(x))} e^{-\lambda\left(\alpha^{\log \frac{G(x)}{1-G(x)}}\right)^{\gamma}}\right.}{1-e^{-\lambda\left(\alpha^{\log \frac{G(x)}{1-G(x)}}\right)^{\gamma}}}
$$

and

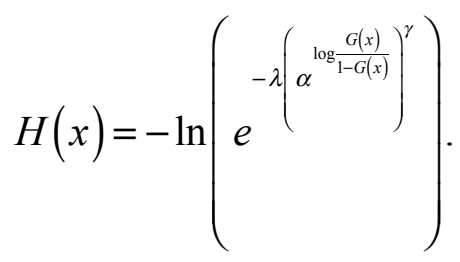

\section{Some Special Sub-Models}

The new-G families of distributions contain as special sub-models various new generated distributions. Some useful distributions in the new-G families are listed in the following subsections.

\section{New Fréchet-Exponential Distribution}

The cdf of the new Fréchet-exponential distribution (NFED) when $X$ follows the standard exponential distribution in (5) is given by

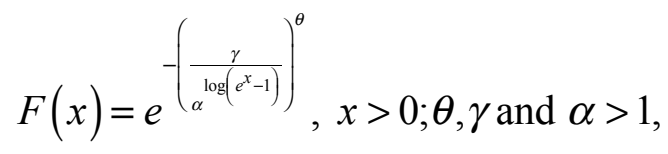

and the corresponding pdf is given by

$$
f(x)=\left(\alpha^{\log \left(1-e^{-x}\right)}\right)^{-\theta} \frac{\theta \gamma^{\theta} \log \alpha}{1-e^{-x}} e^{-\left(\frac{\gamma}{\left.\alpha^{\log \left(e^{x}-1\right)}\right)^{\theta}} .\right.}
$$




\section{A NEW GENERATING FAMILY OF DISTRIBUTIONS}

The survival function, hazard rate function, reversed hazard function and cumulative hazard rate function of the NFED are given respectively by

$$
\begin{gathered}
S(x)=1-e^{-\left(\frac{\gamma}{\alpha^{\log \left(e^{x}-1\right)}}\right)^{\theta}}, \\
h(x)=\frac{\left(\alpha^{\log \left(1-e^{-x}\right)}\right)^{-\theta} \frac{\theta \gamma^{\theta} \log \alpha}{1-e^{-x}} e^{-\left(\frac{\gamma}{\alpha^{\log \left(e^{x}-1\right)}}\right)^{\theta}}}{1-e^{-\left(\frac{\gamma}{\alpha^{\log \left(e^{x-1}\right)}}\right)^{\theta}},} \\
\tau(x)=\left(\alpha^{\log \left(1-e^{-x}\right)}\right)^{-\theta} \frac{\theta \gamma^{\theta} \log \alpha}{1-e^{-x}},
\end{gathered}
$$

and

$$
H(x)=-\ln \left(1-e^{-\left(\frac{\gamma}{\log ^{\left(x^{\theta}-1\right)}}\right)^{\theta}}\right) .
$$

Plots of the pdf and hazard rate function of the NFED are displayed in Figures 1 and 2 respectively for selected parameter values. It is clear from Figure 1 that the NFED densities take various shapes such as right skewed and unimodal. Also, Figure 2 indicates that NFED hrfs can have increasing, constant and U-shape. 


\section{EL-SHERPIENY ET AL.}

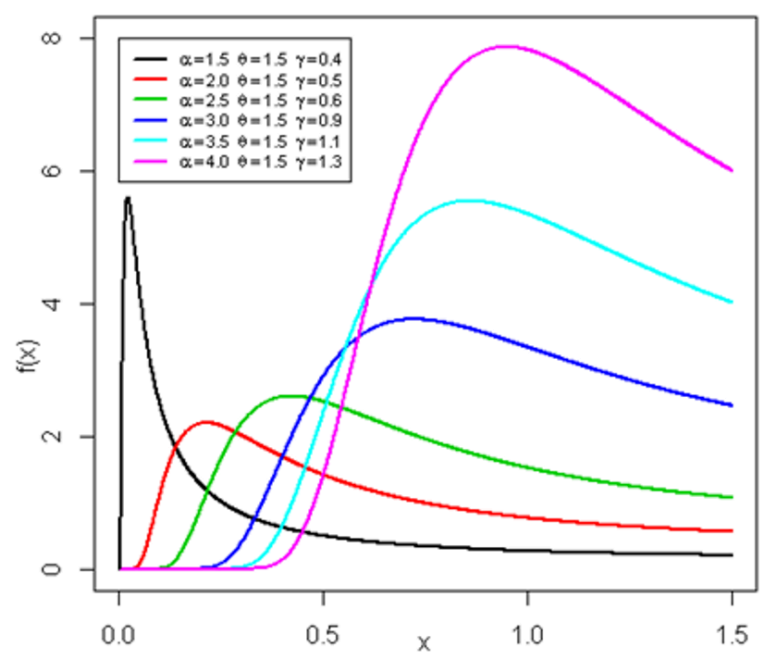

Figure 1. Plots of the pdf of the NFED for some parameter values

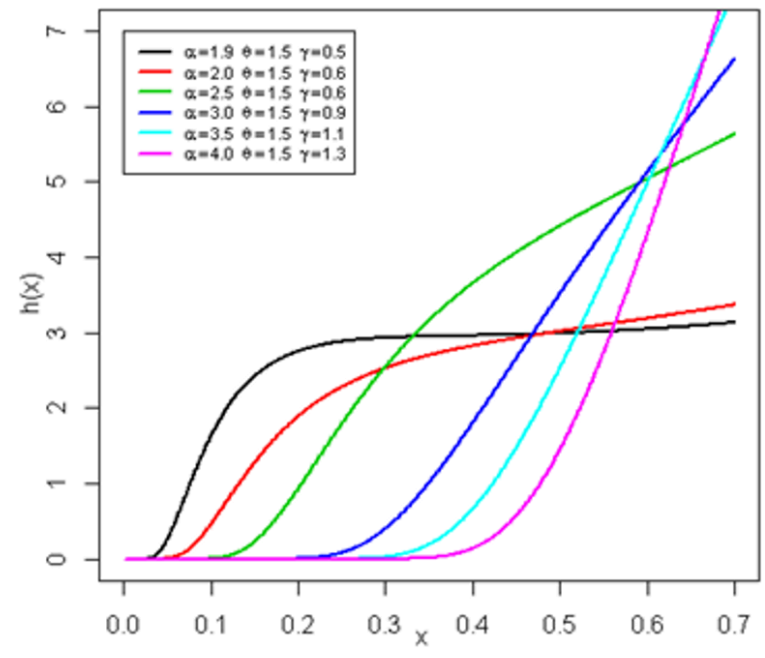

Figure 2. Plots of the hazard rate function of the NFED for some parameter values

\section{New Lomax-Exponential Distribution}

The cdf of the new Lomax-exponential distribution (NLED) when $X$ follows the standard exponential distribution in (7) is given by 


\section{A NEW GENERATING FAMILY OF DISTRIBUTIONS}

$$
F(x)=1-\left(1+\lambda \alpha^{\log \left(e^{x}-1\right)}\right)^{-k}, x>0 ; \lambda, k>0, \alpha>1
$$

and the corresponding pdf is given by

$$
f(x)=\alpha^{\log \left(e^{x}-1\right)} \frac{\lambda k \log \alpha}{1-e^{-x}}\left(1+\lambda \alpha^{\log \left(e^{x}-1\right)}\right)^{-k-1} .
$$

The survival function, hazard rate function, reversed hazard function and cumulative hazard rate function of the (NLED) are given respectively by

$$
\begin{gathered}
S(x)=\left(1+\lambda \alpha^{\log \left(e^{x}-1\right)}\right)^{-k}, \\
h(x)=\frac{\alpha^{\log \left(e^{x}-1\right)} \frac{\lambda k \log \alpha}{1-e^{-x}}}{1+\lambda \alpha^{\log \left(e^{x}-1\right)}}, \\
\tau(x)=\frac{\alpha^{\log \left(e^{x}-1\right)} \frac{\lambda k \log \alpha}{1-e^{-x}\left(1+\lambda \alpha^{\log \left(e^{x}-1\right)}\right)^{-k-1}}}{1-\left(1+\lambda \alpha^{\log \left(e^{x^{x}-1}\right)}\right)^{-k}}
\end{gathered}
$$

and

$$
H(x)=-\ln \left(\left(1+\lambda \alpha^{\log \left(e^{x}-1\right)}\right)^{-k}\right) .
$$

Plots of the pdf and hazard rate function of NLED distribution for some parameter values are displayed in Figures 3 and 4 respectively. 


\section{EL-SHERPIENY ET AL.}

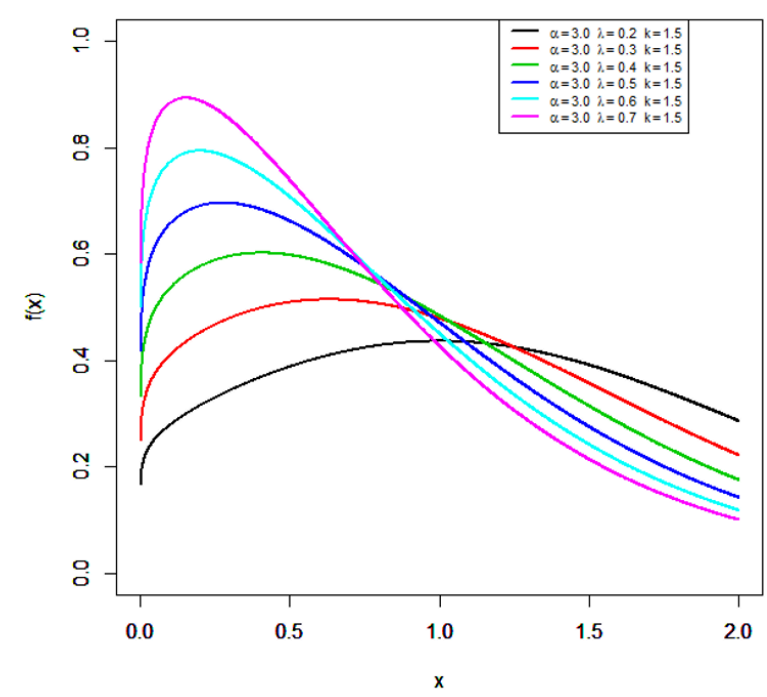

Figure 3. Plots of the pdf of the NLED for some parameter values

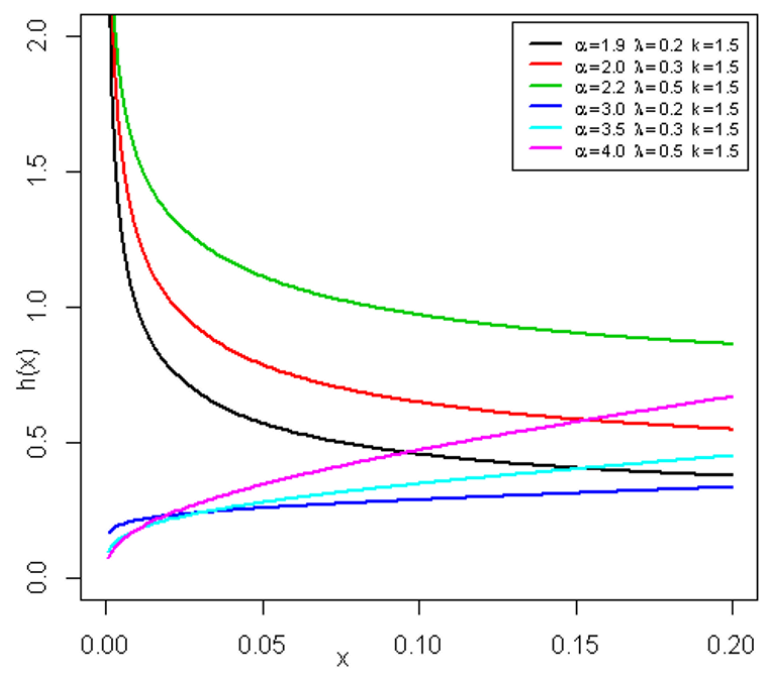

Figure 4. Plots of the hazard rate function of the NLED for some parameter values

\section{New Weibull-Exponential Distribution}

The cdf of the new Weibull-exponential distribution (NWED) when $X$ follows the standard exponential distribution in (11) is given by 


\section{A NEW GENERATING FAMILY OF DISTRIBUTIONS}

$$
F(x)=1-e^{-\lambda \alpha^{\log \left(x^{2}-1\right)^{\gamma}}}, x>0 ; \lambda, \gamma>0, \alpha>1
$$

and the corresponding pdf is given by

$$
f(x)=\alpha^{\log \left(e^{x}-1\right)^{\gamma}} \frac{\gamma \lambda \log \alpha}{1-e^{-x}} e^{-\lambda \alpha^{\log \left(e^{x}-1\right)^{\gamma}}} .
$$

The survival function, hazard rate function, reversed hazard function and cumulative hazard rate function of the NWED are given respectively by

$$
\begin{aligned}
& S(x)=e^{-\lambda \alpha^{\log \left(e^{x}-1\right)^{\gamma}}}, \\
& h(x)=\frac{\gamma \lambda \log \alpha}{1-e^{-x}} e^{-\lambda \alpha^{\log \left(e^{x}-1\right)^{\gamma}},}
\end{aligned}
$$

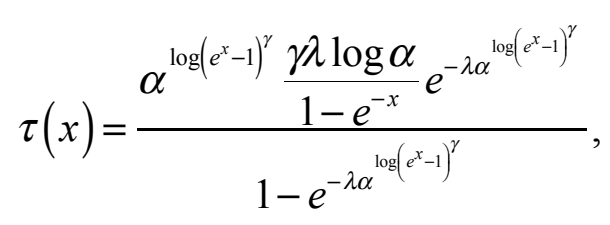

and

$$
H(x)=-\ln \left(e^{-\lambda a^{\log \left(e^{x}-1\right)^{\gamma}}}\right) .
$$

Plots of the pdf and hazard rate function of NWED for some parameter values are displayed in Figures 5 and 6 respectively. 


\section{EL-SHERPIENY ET AL.}

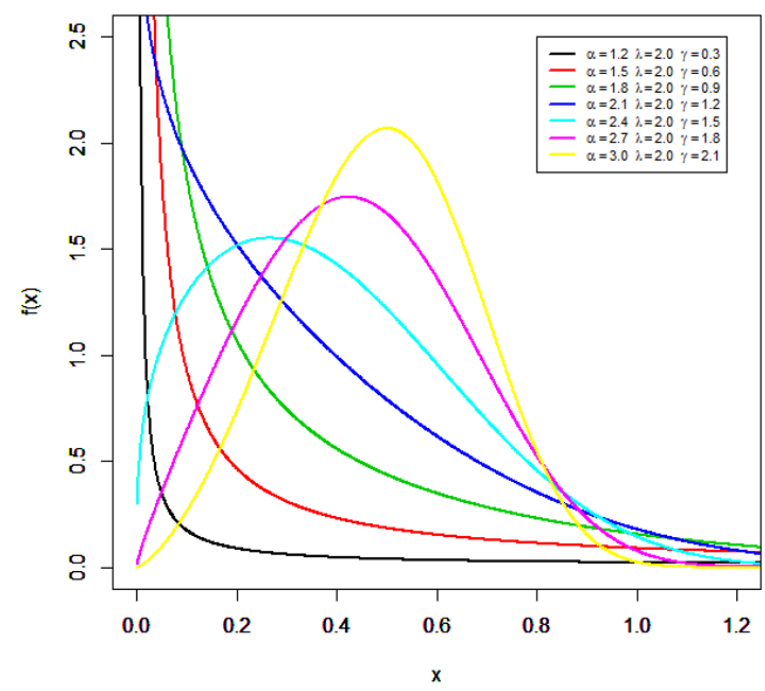

Figure 5. Plots of the pdf of the NWED for some parameter values

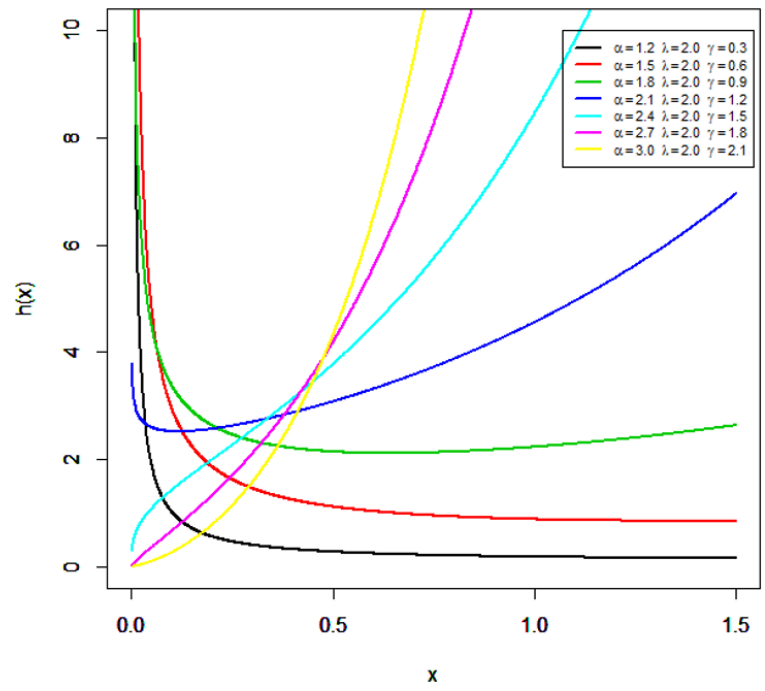

Figure 6. Plots of the hazard rate function of the NWED for some parameter values

The quantile function, say $Q(u)=F^{-1}(u)$ of $X$ which has the NWED is given by 


\section{A NEW GENERATING FAMILY OF DISTRIBUTIONS}

$$
u=1-e^{-\lambda \alpha^{\log \left(e^{Q(u)}-1\right)^{\gamma}}},
$$

after some simplifications, it reduces to the following form

$$
Q(u)=\ln \left[\sqrt[\gamma]{\operatorname{Exp}\left[\ln \left[-\frac{\ln (1-u)}{\lambda}\right] \ln (\alpha)\right]+1},\right.
$$

where, $u$ is considered as a uniform random variable on the unit interval $(0,1)$. In particular, the median can be derived from (15) by setting $u=0.5$. That is, the median is given by

$$
\text { median }=\ln \left[\gamma \sqrt{\operatorname{Exp}\left[\ln \left[-\frac{\ln (0.5)}{\lambda}\right] \ln (\alpha)\right]+1} .\right.
$$

\section{Maximum Likelihood Estimation}

The maximum likelihood estimates (MLEs) of the unknown parameters for the NWED are determined based on complete samples. Let $X_{1}, X_{2}, \ldots, X_{n}$ be observed values from the NWED with set of parameters $\varphi=(\alpha, \lambda, \gamma)^{T}$. The total loglikelihood function for the vector of parameters $\varphi$ can be expressed as

$$
\begin{aligned}
\ln L(\varphi) & =n \ln (\gamma)+n \ln (\lambda)+n \ln (\log \alpha) \\
& +\ln (\alpha) \sum_{i=1}^{n} \log \left(e^{x_{i}}-1\right)^{\gamma}-\sum_{i=1}^{n} \ln \left(1-e^{-x_{i}}\right)-\lambda \sum_{i=1}^{n} \alpha^{\log \left(e^{x_{i}}-1\right)^{\nu}} .
\end{aligned}
$$

The elements of the score function $U(\varphi)=\left(U_{\alpha}, U_{\lambda}, U_{\gamma}\right)$ are given by

$$
\begin{gathered}
U_{\alpha}=\frac{n}{\alpha \log \alpha}+\frac{1}{\alpha} \sum_{i=1}^{n} \log \left(e^{x_{i}}-1\right)^{\gamma} \lambda \sum_{i=1}^{n} \log \left(e^{x_{i}}-1\right)^{\gamma} \alpha^{-1+\log \left(e^{x_{i}}-1\right)^{\nu}}, \\
U_{\lambda}=\frac{n}{\lambda}-\sum_{i=1}^{n} \alpha^{\log \left(e^{x_{i}}-1\right)^{\nu}} .
\end{gathered}
$$




\section{EL-SHERPIENY ET AL.}

and

$$
\begin{aligned}
U_{\gamma} & =\frac{n}{\gamma}-\ln (\alpha) \sum_{i=1}^{n} \frac{\left(e^{x_{i}}-1\right)^{\gamma} \log \left(e^{x_{i}}-1\right)}{\left(e^{x_{i}}-1\right)^{\gamma}} \\
& -\lambda \log \alpha \sum_{i=1}^{n} \frac{\alpha^{\log \left(e^{x_{i}}-1\right)^{y}}\left(e^{x_{i}}-1\right)^{\gamma} \log \left(e^{x_{i}}-1\right)}{\left(e^{x_{i}}-1\right)^{\gamma}} .
\end{aligned}
$$

The maximum likelihood estimates of the parameters $\alpha, \lambda$ and $\gamma$ are obtained by setting Equations (16-18) to be zero and solving them. Clearly, there is no closed solution for the above non-linear equations, so an extensive numerical solution will be applied via iterative technique. Therefore, the Newton-Raphson's iteration method can be applied and used the computer package such as Maple or R or other software.

\section{Simulation}

It is difficult to compare the theoretical performances of the different estimators (MLEs) for the NWED. Therefore, simulation is needed to compare the performances of the different methods of estimation mainly with respect to their biases, mean square errors and Variances (MLEs) for different sample sizes. A numerical study is performed using Mathematica 7 software. Different sample sizes are considered through the experiments at size $n=20,30,50,100,200$ and 300. In addition, the different values of parameters $\alpha, \lambda$ and $\gamma$.

The experiment will be repeated 1000 times. In each experiment, the estimates of the parameters will be obtained by maximum likelihood methods of estimation. The means, MSEs and biases for the different estimators will be reported from these experiments.

\section{Application}

A real data set is used to illustrate the importance and flexibility of the NWED. We compare the fits of the NWED model with some models namely: the alpha power transformed Weibull (APTW) (Dey et al., 2017), Marshal-Olkin Weibull (MOW) (Marshal and Olkin, 1997), Very flexible weibull (VFW) (Ahmad, 2017) and Kumaraswamy Weibull (Ku-W) (Cordeiro et al., 2010) distributions. The 


\section{A NEW GENERATING FAMILY OF DISTRIBUTIONS}

maximized log-likelihood $(-2 \ell)$, Akaike information criterion (AIC), the corrected Akaike information criterion (CAIC), Bayesian information criterion (BIC), and Hannan-Quinn information criterion (HQIC), statistics are used for model selection. More information can be provided in Figures 7 and 8. Also PP-plots are shown in Figures 8 for the real data.

Table 2. The parameter estimation from NWED using MLE

\begin{tabular}{|c|c|c|c|c|c|c|c|c|c|}
\hline$n$ & Params & Init & MLE & Bais & MSE & Init & MLE & Bais & MSE \\
\hline \multirow{3}{*}{20} & $\alpha$ & 1.9 & 4.14262 & 2.24262 & 5.13795 & 1.9 & 4.71060 & 2.81060 & 8.05459 \\
\hline & $\mathrm{Y}$ & 1.5 & 1.74853 & 0.24853 & 0.11193 & 2.0 & 2.13902 & 0.13902 & 0.09590 \\
\hline & $\lambda$ & 2.5 & 2.79363 & 0.29363 & 0.85860 & 2.5 & 2.81134 & 0.31134 & 0.82198 \\
\hline \multirow{3}{*}{30} & $\alpha$ & 1.9 & 4.11939 & 2.21939 & 4.99652 & 1.9 & 4.68207 & 2.78207 & 7.85143 \\
\hline & $\mathrm{Y}$ & 1.5 & 1.73180 & 0.23180 & 0.08607 & 2.0 & 2.11818 & 0.11818 & 0.06873 \\
\hline & $\lambda$ & 2.5 & 2.70896 & 0.20896 & 0.42179 & 2.5 & 2.69311 & 0.19311 & 0.45953 \\
\hline \multirow{3}{*}{50} & $\alpha$ & 1.9 & 4.08096 & 2.18096 & 4.79733 & 1.9 & 4.62904 & 2.72904 & 7.50431 \\
\hline & $\mathrm{Y}$ & 1.5 & 1.70515 & 0.20515 & 0.06056 & 2.0 & 2.08017 & 0.08017 & 0.03382 \\
\hline & $\lambda$ & 2.5 & 2.61272 & 0.11273 & 0.19481 & 2.5 & 2.61463 & 0.11463 & 0.20961 \\
\hline \multirow{3}{*}{100} & $\alpha$ & 1.9 & 4.05615 & 2.15615 & 4.66861 & 1.9 & 4.59809 & 2.69809 & 7.30487 \\
\hline & $\mathrm{r}$ & 1.5 & 1.68792 & 0.18792 & 0.04415 & 2.0 & 2.05796 & 0.05796 & 0.01544 \\
\hline & $\lambda$ & 2.5 & 2.54982 & 0.04982 & 0.07937 & 2.5 & 2.55132 & 0.05132 & 0.07704 \\
\hline \multirow{3}{*}{20} & $\alpha$ & 2.2 & 4.29472 & 2.09472 & 4.50716 & 1.5 & 5.85642 & 4.35642 & 19.2489 \\
\hline & $\mathrm{Y}$ & 2.0 & 1.85193 & -0.14810 & 0.07800 & 2.0 & 2.97081 & 0.97081 & 1.09319 \\
\hline & $\lambda$ & 2.5 & 2.81095 & 0.31095 & 1.05974 & 1.5 & 1.62149 & 0.12149 & 0.21440 \\
\hline \multirow{3}{*}{30} & $\alpha$ & 2.2 & 4.27166 & 2.07166 & 4.37322 & 1.5 & 5.79974 & 4.29974 & 18.6579 \\
\hline & $\mathrm{Y}$ & 2.0 & 1.83502 & -0.16500 & 0.06516 & 2.0 & 2.92721 & 0.92721 & 0.95197 \\
\hline & $\lambda$ & 2.5 & 2.71553 & 0.21553 & 0.42753 & 1.5 & 1.57231 & 0.07231 & 0.12419 \\
\hline \multirow{3}{*}{50} & $\alpha$ & 2.2 & 4.23508 & 2.03508 & 4.18275 & 1.5 & 5.75801 & 4.25801 & 18.2302 \\
\hline & $\mathrm{r}$ & 2.0 & 1.80928 & -0.19070 & 0.05536 & 2.0 & 2.89519 & 0.89519 & 0.85588 \\
\hline & $\lambda$ & 2.5 & 2.61038 & 0.11038 & 0.20311 & 1.5 & 1.52970 & 0.02970 & 0.05124 \\
\hline \multirow{3}{*}{100} & $\alpha$ & 2.2 & 4.20321 & 2.00321 & 4.03231 & 1.5 & 5.72126 & 4.22126 & 17.8714 \\
\hline & Y & 2.0 & 1.78709 & -0.21290 & 0.05427 & 2.0 & 2.86747 & 0.86747 & 0.78100 \\
\hline & $\lambda$ & 2.5 & 2.53574 & 0.03574 & 0.07586 & 1.5 & 1.52523 & 0.02523 & 0.02492 \\
\hline
\end{tabular}




\section{EL-SHERPIENY ET AL.}
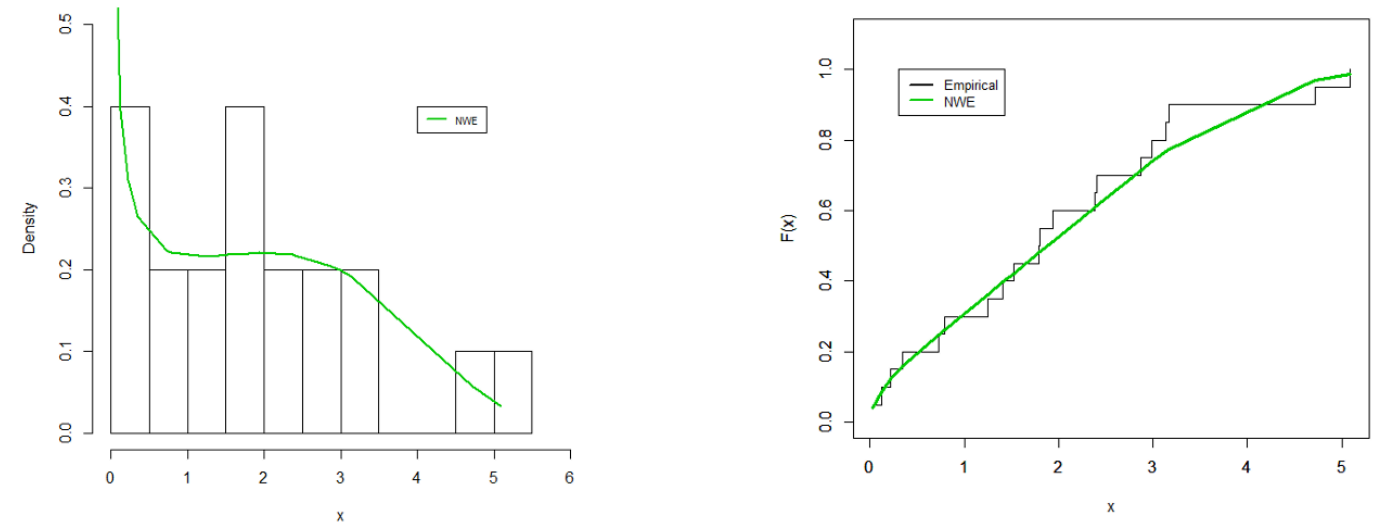

Figure 7. Estimated pdf and cdf of NWE for the data set.
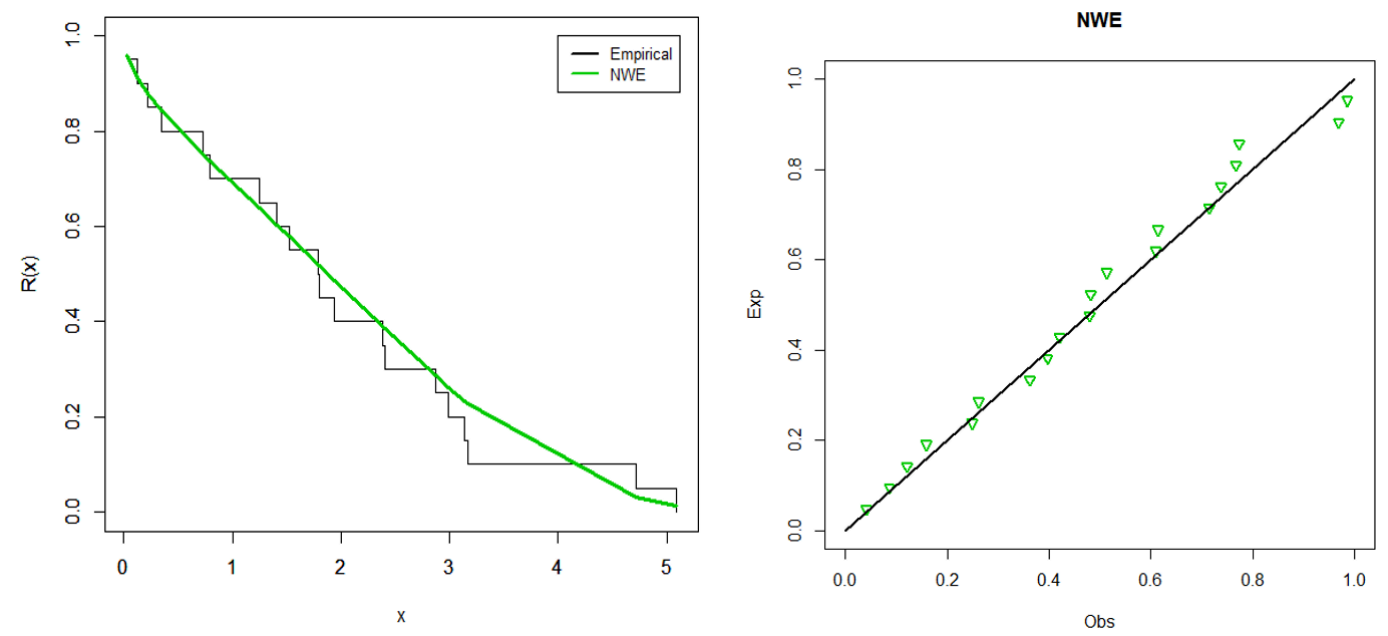

Figure 8. Estimated survival function and pp plots of NWE for the data set.

The data set was first analyzed by Teimouri and Gupta (2013). The data are summarized in Table 3.

Table 3. Lifetimes of 20 electronic components.

\begin{tabular}{ll}
\hline & $0.03,0.12,0.22,0.35,0.73,0.79,1.25$, \\
Data Set & $1.41,1.52,1.79,1.80,1.94,2.38,2.40$, \\
& $2.87,2.99,3.14,3.17,4.72,5.09$
\end{tabular}




\section{A NEW GENERATING FAMILY OF DISTRIBUTIONS}

For the data set, Table 4 gives the MLEs of the fitted models and their standard errors (SEs) in parenthesis. The values of goodness-of-fit statistics are listed in Table 5 .

Table 4. Maximum likelihood estimates of the fitted distributions using data set.

\begin{tabular}{lrrrrrr} 
Dist. & $\hat{\alpha}$ & $\hat{\gamma}$ & $\hat{\lambda}$ & $\hat{\theta}$ & $\hat{a}$ & $\hat{b}$ \\
\hline Proposed & 3.045 & 0.484 & 0.275 & & & \\
APTW & 5.189 & 1.014 & 0.704 & & & \\
MOW & 6.292 & 0.815 & 1.308 & & & \\
VFW & 0.073 & 0.494 & 0.892 & & & \\
Ku-W & & 2.659 & 0.071 & & 0.268 & 0.558 \\
\hline
\end{tabular}

Table 5. The statistics of the fitted models using data set.

\begin{tabular}{lrrrrrrr} 
Dist. & KS & CM & AD & AIC & BIC & CIAC & HQIC \\
\hline Proposed & 0.125 & 0.032 & 0.261 & 69.390 & 72.380 & 70.890 & 69.980 \\
APTW & 0.141 & 0.055 & 0.333 & 70.910 & 73.900 & 72.410 & 71.490 \\
MOW & 0.139 & 0.040 & 0.265 & 70.200 & 73.180 & 71.700 & 70.780 \\
VFW & 0.165 & 0.263 & 1.620 & 71.490 & 74.480 & 72.990 & 72.070 \\
Ku-W & 0.169 & 0.271 & 0.195 & 71.980 & 74.891 & 73.570 & 72.890 \\
\hline
\end{tabular}

It is noted, from Table 5 that the NWED distribution provides a better fit than other competitive fitted models. It has the smallest values for goodness-of-fit statistics among all fitted models.

\section{Conclusion}

A new method for generating family of distributions called the new T-X family is introduced. Some of its properties are derived and some members of the family are defined. New sub-models of the family are studied. Maximum likelihood estimators of the parameters for NWED are derived. The NWED has the ability to fit the data set better than competing distributions.

\section{References}

Ahmad, Z. (2017). Very Flexible Weibull Distribution. MAYFEB Journal of Mathematics, 2, 61-73. 


\section{EL-SHERPIENY ET AL.}

Ahmad, Z., Elgarhy, M. and Hamedani, G. G. (2018). A New Weibull-X family of distributions: properties, characterizations and applications. Journal of Statistical Distributions and Applications, 5(1), 1-18. https://doi.org/10.1186/s40488-018-0087-6

Aldahlan, M. A., Jamal, F., Chesneau, Ch., Elgarhy, M. and Elbatal, I. (2020). The Truncated Cauchy Power Family of Distributions with Inference and Applications.

Entropy, 22(3), 1-25. https://doi.org/10.3390/e22030346

Alexander, C., Cordeiro, G. M., Ortega, E. M. M., and Sarabia, J. M. (2012). Generalized beta generated distributions. Computational Statistics and Data Analysis, 56(6), 1880-1897. https://doi.org/10.1016/j.csda.2011.11.015

Alizadeh, M., Tahir, M. H., Cordeiro, G. M., Mansoor, M., Zubair, M., and Hamedani, G. G. (2015). The Kumaraswamy Marshal-Olkin family of distributions. Journal of the Egyptian Mathematical Society, 23(3), 546-557. https://doi.org/10.1016/j.joems.2014.12.002

Almarashi, A. M. and Elgarhy, M. (2018). A new muth generated family of distributions with applications. Journal of Nonlinear Science and Applications, 11(10), 1171-1184. https://doi.org/10.22436/jnsa.011.10.06

Al-Marzouki, S., Jamal, F., Chesneau, C. and Elgarhy, M. (2020). Topp-Leone Odd Fréchet Generated Family of Distributions with Applications to COVID-19 Data Sets. Computer Modeling in Engineering \& Sciences, 125(1), 437-458. https://doi.org/10.32604/cmes.2020.011521

Alzaatreh, A., Lee, C. \&Famoye, F. (2013). A new method for generating families of continuous distributions. Metron, 71(1), 63-79. https://doi.org/10.1007/s40300-0130007-y

Alzaatreh, A., Famoye, F. and Lee, C. (2014). The gamma-normal distribution: Properties and applications. Computational Statistics and Data Analysis, 69, 67-80. https://doi.org/10.1016/j.csda.2013.07.035

Alzaghal, A., Famoye, F., and Lee, C. (2013). Exponentiated T-X family of distributions with some applications. International journal of statistics and probability, 2(3), 31-49. https://doi.org/10.5539/ijsp.v2n3p31

Badr, M. M., Elbatal, I., Jamal, F., Chesneau, Ch. and Elgarhy, M. (2020). The Transmuted Odd Fréchet-G family of distributions: theory and applications. Mathematics, 8(6), 1-20. https://doi.org/10.3390/math8060958

Cordeiro, G. M., Ortega, E. M., and Nadarajah, S. (2010). The Kumaraswamy Weibull distribution with application to failure data. J Franklin Inst, 347(8), 1399-1429. https://doi.org/10.1016/j.jfranklin.2010.06.010 


\section{A NEW GENERATING FAMILY OF DISTRIBUTIONS}

Cordeiro, G. M., Hashimoto, E. M., and Ortega, E. M. (2012). The McDonald Weibull model. Statistics, 48(2), 256-278.

https://doi.org/10.1080/02331888.2012.748769

Cordeiro, G. M., Alizadeh, M., Ozel, G., Hosseini, B., Ortega, E. M. M., and Altun, E. (2017). The generalized odd log-logistic family of distributions: properties, regression models and applications. Journal of Statistical Computation and Simulation, 87(5), 908932. https://doi.org/10.1080/00949655.2016.1238088

Dey, S., Sharma, V. K., and Mesfioui, M. (2017). A new extension of Weibull distribution with application to lifetime data. Annals of Data Science, 4(1), 31-61. https://doi.org/10.1007/s40745-016-0094-8

Elgarhy, M., Haq, M.A., Ozel, G. and Nasir, M. A. (2017). A New Exponentiated Extended Family of Distributions with Applications. Gazi University Journal of Science, 30(3), 101-115.

Elgarhy, M., Hassan, A.S. and Rashed, M. (2016). Garhy-Generated Family of Distributions with Application. Mathematical Theory and Modeling, 6, 1-15.

Eugene, N., Lee C., and Famoye, F. (2002). Beta-normal distribution and its applications. Communication in Statistics - Theory Methods, 31(4), 497-512. https://doi.org/10.1081/sta-120003130

Haq, M. and Elgarhy, M. (2018). The odd Frèchet-G family of probability distributions. Journal of Statistics Applications \& Probability, 7(1), 185-201. https://doi.org/10.18576/jsap/070117

Hassan, A. S. and Elgarhy, M. (2016). Kumaraswamy Weibull-generated family of distributions with applications. Advances and Applications in Statistics, 48(3), 205-239. https://doi.org/10.17654/as048030205

Hassan, A. S. \& Elgarhy, M., and Shakil, M. (2017). Type II Half Logistic Family of Distributions with Applications. Pakistan Journal of Statistics and Operation Research, 13(2), 245-264. https://doi.org/10.18187/pjsor.v13i2.1560

Marshall, A. W. and Olkin, I. (1997). A new method for adding a parameter to a family of distributions with application to the exponential and Weibull families.

Biometrika, 84(3), 641-652. https://doi.org/10.1093/biomet/84.3.641

Ristić, M. M., and Balakrishnan, N. (2012). The gamma-exponentiated exponential distribution. Journal of Statistical Computation and Simulation, 82(8), 1191-1206. https://doi.org/10.1080/00949655.2011.574633

Tahir, M. H., Cordeiro, G. M., Alizadeh, M., Mansoor, M., Zubair, M., and Hamedani, G. G. (2015). The odd generalized exponential family of distributions with 


\section{EL-SHERPIENY ET AL.}

applications. Journal of Statistical Distributions and Applications, 2(1), https://doi.org/10.1186/s40488-014-0024-2.

Teimouri, M., and Gupta, A. K. (2013). On the three-parameter Weibull distribution shape parameter estimation. Journal of Data Science, 11(3), 403-414. https://doi.org/10.6339/jds.2013.11(3).1110

Torabi, H. and Montazari, N. H. (2012). The gamma-uniform distribution and its application. Kybernetika, 48, 16-30.

Torabi, H. and Montazari, N. H. (2014). The logistic-uniform distribution and its applications. Communications in Statistics - Simulation and Computation, 43(10), 25512569. https://doi.org/10.1080/03610918.2012.737491

Zografos, K. and Balakrishnan, N. (2009). On families of beta- and generalized gamma-generated distributions and associated inference. Statistical Methodology, 6(4), 344-362. https://doi.org/10.1016/j.stamet.2008.12.003 